\title{
PEMANFAATAN MEDIA RADIO DI ERA DIGITAL
}

\author{
Meilani Dhamayanti
}

Program Studi Ilmu Komunikasi, Universitas Bina Nusantara; mdhamayanti73@gmail.com

\begin{abstract}
Indonesian)
Radio merupakan salah satu media massa yang disukai oleh masyarakat Indonesia untuk mendapatkan hiburan maupun informasi. Karateristik radio yang akrab (memiliki keekatan emosi) membuat pendengar merasa informasi dan hiburan yang diterima lebih spesifik. Perkembangan jaman serta kemajuan teknologi audio visual yang ditandai dengan kemunculan media televisi membuat radio perlahan tergeser, namun radio masih memiliki tempat di hati pemirsanya. Sifat radio yang auditif membuat pemirsanya mampu mengerjakan kegiatan lain sekaligus. Era digital, peminat radio masih kalangan generasi X dan Y. Generasi milenial yang menikmati radio sebatas untuk hiburan mendengarkan music. Mereka lebih memilih media lain untuk mengakses informasi. Radio streaming tidak selalu dinikmati oleh semua kalangan. Kalangan generasi X dan Y masih memilih radio dari smartphone mereka. Penelitian ini bertujuan untuk mengetahui bagaimana pemanfaatan media radio di era digital. Penelitian ini menggunakan metoda kualitatif dengan menggunakan wawancara kepada sejumlah narasumber sebagai teknik pengumpul data. Narasumber yang diwawancarai sejumlah 4 orang dengan berbagai latar belakang. Hasil penelitian diketahui bahwa radio masih menjadi disukai sejumlah kalangan termasuk generasi milenial. Pemanfaatan radio dengan berbagai alasan diantaranya : hiburan dan informasi. Saran : pengelola radio harus dapat memanfaatkan kemajuan teknologi dengan menyelenggarakan media radio berbasis internet dengan program yang lebih variatif.
\end{abstract}

Keywords: Radio, milineal, digital, media audio

\begin{abstract}
Radio is one of the mass media favored by the people of Indonesia to get entertainment and information. The familiar radio characteristics (having emotional closeness) make the listener feel the information and entertainment received is more specific. The development of the era and the advancement of audio visual technology which is marked by the emergence of television media makes the radio slowly shifted, but the radio still has a place in the hearts of its viewers. The auditive nature of the radio makes the audience able to do other activities at once. The digital age, radio enthusiasts are still among the $X$ and $Y$ generations. Millennials who enjoy radio are limited to entertainment listening to music. They prefer other media to access information. Streaming radio is not always enjoyed by all people. Generation $X$ and $Y$ still choose radio from their smartphones. This study aims to determine how the use of radio media in the digital age. This study uses a qualitative method using interviews with a number of sources as data collection techniques. The interviewees numbered 4 people from various backgrounds. The results of the study note that radio is still a favorite among a number of people including millennial generation. The use of radio for various reasons including: entertainment and information. Suggestion: radio managers should be able to take advantage of technological advancements by organizing internet-based radio media with more varied programs.
\end{abstract}

Keywords: Radio, milineal, digital, media audio 


\section{NARK \\ Jurnal Ranah Komunikasi \\ 1. INTRODUCTION}
E-ISSN : 2656-4718
P-ISSN : 2302-8106
Jurnal Ranah Komunikasi (JRK)
Volume 3 Nomor 2 Tahun 2019

Radio merupakan salah satu media massa yang disukai oleh masyarakat Indonesia untuk mendapatkan hiburan maupun informasi. Karateristik radio yang akrab (memiliki keekatan emosi) membuat pendengar merasa informasi dan hiburan yang diterima lebih spesifik. Perkembangan jaman membuat media radio semakin terpinggirkan namun tetap diminati sebagian kalangan. Kehadiran smartphone memungkinkan radio dapat dinikmati dimanapun tanpa harus membawa perangkat fisik radio.

Sejarah mencatat radio pernah menjadi primadona di masanya. Di Indonesia sejarah perkembangan radio cukup panjang bahkan mewarnai perjuangan bangsa Indonesia. Peranan radio di era kemerdekaan sangat besar bagi pejuang Indonesia. Radio pertama di Indonesia ialah Bataviase Radio Vereningin (BRV) di Batavia (Jakarta tempo dulu) yang resminya didirikan tanggal 16 Juni 1925. Kemunculan BRV diiikuti oleh radio swasta lainnya di daerah. Peranan radio saat itu menjadi hiburan sekaligus penyemangat perjuangan.

Perkembangan jaman serta kemajuan teknologi audio visual yang ditandai dengan kemunculan media televisi membuat radio perlahan tergeser. Kelebihan visual membuat televisi lebih disukai banyak kalangan. Kehadiran TV swasta dengan beragam acara membuat televisi menjadi primadona menggantikan radio. Kalangan yang masih bertahan menjadi pendengar radio berkurang namun tetap solid. Kelebihan radio membuat media ini tetap memiliki tempat bagi pemirsanya.

Survei Nielsen dari 8.400 orang di 11 kota di Indonesia, radio masih didengarkan oleh 20 juta orang dengan rata-rata durasinya 139 menit per hari. Bila dikategorisasi berdasarkan usianya, Generasi X (35-49 tahun) menempati urutan teratas dengan durasi mendengarkan radio selama 18 jam setiap minggunya. Disusul oleh Baby Boomers (50-56 tahun) selama 17 jam 20 menit, silent generation (65 tahun ke atas) selama 16 jam 22 menit, dan millennial (15-34 tahun) selama 15 jam 37 menit. ${ }^{1}$ Hasil rekapitulasi Kominfo per 2019, jumlah radio yang memiliki izin mengudara sebanyak 2025. Terdiri dari 1.680 Lembaga Penyiaran Swasta (LPS), 215 Lembaga Penyiaran Komunitas (215), dan 130 Lembaga Penyiaran Publik Lokal (LPPL).

\footnotetext{
${ }^{1}$ www.nielsen.com diakses tanggal 15/5/2016
} 


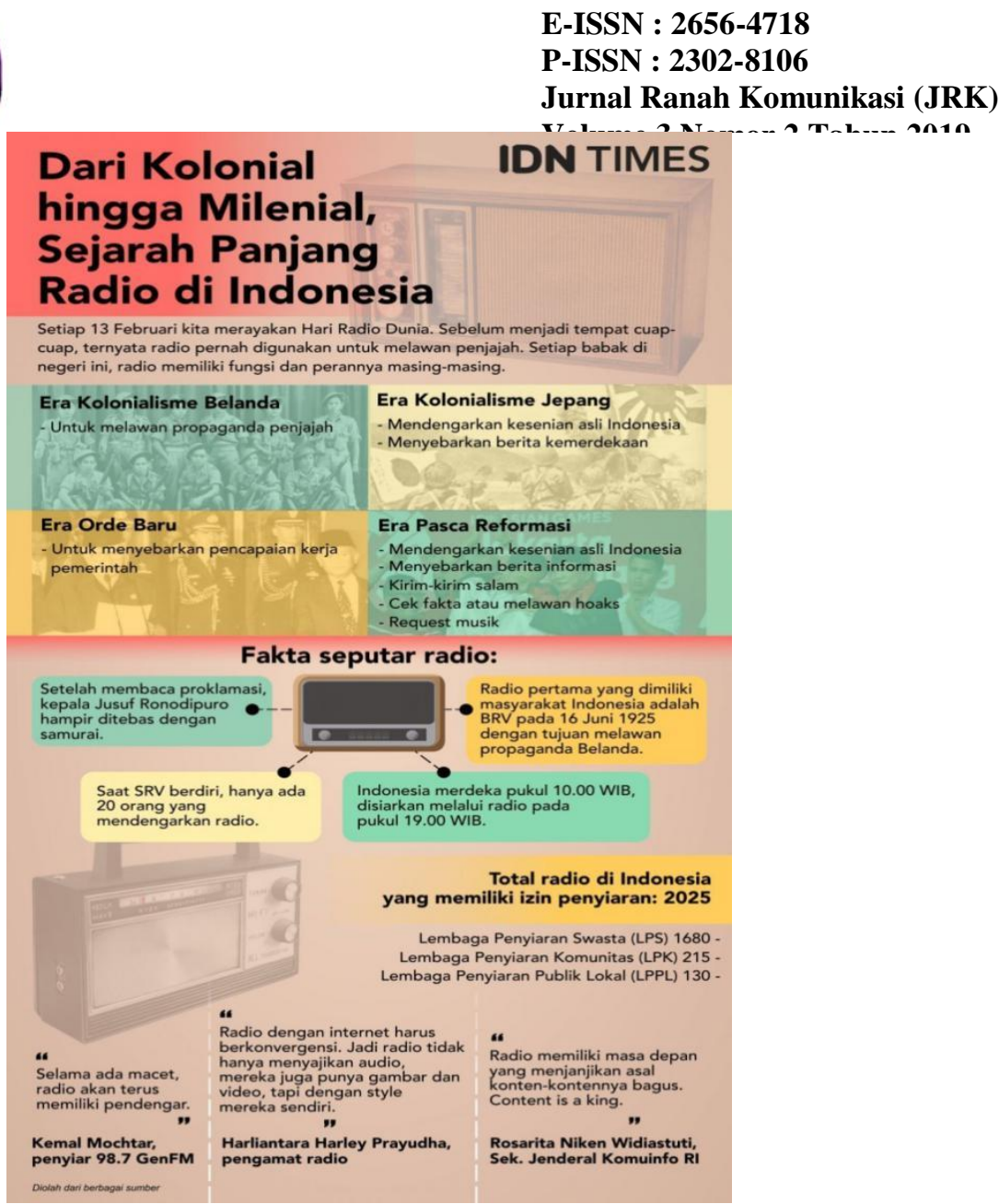

Gambar.1 Radio dari era ke era

Sumber: idn Times, 2019

Perkembangan teknologi komunikasi yang begitu pesat melahirkan berbagai inovasi media. Konvergensi media adalah salah satu inovasi di bidang media yang menggabungkan media massa dengan teknologi digital. Radio streaming merupakan salah satu contoh konvergensi media yang cukup disenangi. Konvergensi media membuat radio kembali eksis, seperti sebelum ditemukannya televisi.

Radio streaming memberikan kemudahan bagi penikmat radio dapat mendengarkan dimanapun berada. Kendala jarak bukan menjadi halangan seperti era sebelumnya. Radio streaming membuat radio kembali digemari bukan hanya oleh orangtua, yaitu generasi penikmat radio di era sebelumnya tetapi juga diminati anak muda. Sebagai Sekretaris Jenderal Kominfo, Niken melihat potensi radio sebagai sarana cek fakta yang cepat. Dengan melemparkan satu isu ke ruang publik, ia berharap masyarakat bisa terlibat aktif dalam memberantas hoaks di jejaring pemberitaan.

Bagi Harliantara, radio memiliki keuntungan bagi pendengar dan penyiarnya. Dalam menyampaikan informasi, radio memiliki nilai persuasif yang tinggi. Untuk skala lokal, radio 
masih menjadi media informasi yang terus mendapat ruang di setiap hati pendengarnya. "Karena ada kedekatan emosi," terang dia. Sedangkan, bagi penyiarnya, radio menjadi kawah candradimuka untuk meningkatkan kualitas diri. "Radio itu kan isinya orang-orang kreatif, harus multitasking dong. Bisa MC, public speaking, moderator, jadi reporter, itu nilai tambah. Jadi kompetensinya terus meningkat," sambungnya.

Radio adalah sebuah teknologi yang digunakan untuk pengiriman sinyal dengan cara modulasi dan radiasi elektromagnetik (gelombang elektromagnetik). Gelombang ini melintas dan merambat lewat udara dan bisa juga merambat lewat ruang angkasa yang hampa udara, karena gelombang ini tidak memerlukan medium pengangkut (seperti molekul udara). ${ }^{2}$ Radio juga merupakan alat komunikasi massa, dalam artian saluran pernyataan manusia umumnya/terbuka dan menyalurkan gelombang yang berbunyi, berupa program-program yang teratur yang isinya aktual dan meliputi segi perwujudan kehidupan masyarakat. ${ }^{3}$

Radio mempunyai ciri dan sifat yang berbeda dengan media massa lainnya. Radio bersifat auditif terbatas pada suara atau bunyi yang menerpa pada indra. Karnanya tidak menuntut khalayak memiliki kemampuan membaca, tidak menuntut kemampuan melihat, melainkan hanya kemampuan untuk mendengarkan. Frank Jefkins mengemukakan karakteristik media radio yang menguntungkan (1996 : 101) yaitu: a. Murah, b. Waktu transmisi tidak terbatas, c. Suara manusia dan music, d. Tidak memerlukan perhatian terfokus, e. Teman setia

Pendengar radio memiliki karateristik yang berbeda dengan media massa lainnya. Karateristik pendengar radio ${ }^{4}$, meliputi : a. Heterogen, massa pendengar terdiri dari orangorang berbeda usia, ras, suku, agama, strata sosial, latar belakang sosial, politik, budaya, dan beranekaragam kepentingan. $\mathrm{b}$. Pribadi, pendengar adalah individu-individu yang berdiri sendiri, bukanlah tim kelompok. Komunikasi yang berlangsung berusaha menciptakan kedekata antar pribadi, sehingga pendengar bisa merasa nyaman dan pesan yang disampaikan bisa ditangkap dengan baik oleh pendengar. c. Aktif.

Ada lima asumsi dasar teori uses and gratifications yaitu: 1) Khalayak aktif dan penggunaan medianya berorientasi pada tujuan; 2) Inisiatif dalam menghubungkan kepuasan kebutuhan pada pilihan media tertentu terdapat pada anggota khalayak; 3) Media berkompetisi dengan sumber lainnya untuk kepuasan kebutuhan; 4) Orang mempunyai cukup

\footnotetext{
2 Syamsul, Asep dan Romli, M. : Dasar-Dasar Siaran Radio, (Bandung: Nuansa, 2009) hlm. 12

${ }^{3}$ Arifin, Anwar. Strategi Komunikasi, (Bandung: ARMICO, 1984), hlm. 81

${ }^{4}$ Syamsul, Asep, Romli. Dasar-Dasar Siaran Radio. (Bandung: Nuansa) hlm. 21
} 

sebuah gambaran yang akurat mengenai kegunaan tersebut kepada para peneliti. 5) Penilaian mengenai nilai isi media hanya dapat dinilai oleh khalayak (West \& Turner, 2008).

Teori uses and gratifications ini merupakan kecenderungan yang lebih luas dari pihak media untuk memberikan kepuasan kepada khalayak.. Menurut Katz, Gurevitch, dan Haas, seperti dikutip Effendy dalam bukunya yang berjudul Ilmu, Teori dan Filsafat Komunikasi (1993:294), model Uses and Gratifications memulai dengan lingkungan sosial (social environment) yang menentukan kebutuhan kita. Lingkungan sosial tersebut meliputi ciri-ciri afiliasi kelompok dan ciri-ciri kepribadian. Ada kebutuhan individu yang bilamana terpenuhi dapat mencukupinya sebagai individu atau manusia. Kebutuhan individual (individual's needs) dikategorikan sebagai berikut :

1. Cognitive needs (kebutuhan kognitif). Kebutuhan yang berkaitan dengan peneguhan informasi, pengetahuan dan pemahaman mengenai lingkungan. Kebutuhan ini didasarkan pada hasrat untuk memahami dan menguasai lingkungan; juga memuaskan rasa penasaran kita dan dorongan untuk penyelidikan kita.

2. Affective needs (kebutuhan efektif). Kebutuhan yang berkaitan dengan peneguhan pengalaman-pengalaman yang estetis, menyenangkan, dan emosional.

3. Personal integrative needs (kebutuhan peribadi secara integratif). Kebutuhan yang berkaitan dengan peneguhan kredibilitas, kepercayaan, stabilitas, dan status individual. Hal-hal tersebut diperoleh dari hasrat akan harga diri.

4. Social integrative needs (kebutuhan sosial secara integratif). Kebutuhan yang berkaitan dengan peneguhan kontak dengan keluarga, teman, dan dunia. Hal-hal tersebut didasarkan pada hasrat untuk berfiliasi.

5. Escapist needs (kebutuhan pelepasan). Kebutuhan yang berkaitan dengan upaya menghindarkan tekanan, ketegangan, dan hasrat akan keanekaragaman.

Dalam teori uses and gratifications diaplikasikan pada motif pengguna dalam memanfaatkan media internet sebagai media komunikasi baru untuk memenuhi kebutuhan informasi, hiburan dan identitas personal. Uses and gratification dilandasi pada asumsiasumsi antara lain (Liliweri, 1991):

1. Penggunaan media pada akhirnya untuk mencapai suatu tujuan. Khalayak menggunakan media massa untuk memenuhi kebutuhan-kebutuhan dengan sifatnya yang spesifik. Kebutuhan ini berkembang dengan lingkungan sosial.

2. Khalayak memilih jenis dan isi media massa untuk memenuhi kebutuhannya. Jadi khalayak terlibat dalam suatu proses komunikasi massa dan mereka dapat mempengaruhi media untuk kebutuhan-kebutuhan mereka secara lebih cepat dibandingkan dengan media yang dapat menguasai mereka. 
3. Disamping media massa sebagai sumber informasi, maka ada pula berbagai sumber-sumber lain yang dapat memuaskan kebutuhan khalayak. Oleh karena itu media massa harus lebih bersaing dengan sumber-sumber lainnya.

4. Khalayak mengetahui kebutuhan tersebut dan dapat memenuhinya jika dikehendaki. Mereka juga mengetahui alasan-alasan untuk menggunakan dan memilih media massa.

\section{METHODOLOGY OF RESEARCH}

Dalam penelitian ini peneliti menggunakan pendekatan penelitian kualitatif. Pendekatan kualitatif dapat di definisikan sebagai prosedur penelitian yang menghasilkan data deskriptif berupa kata-kata tertulis atau lisan dari orang dan perilaku yang dapat diamati ${ }^{5}$ Proses pengumpulan data dapat dilakukan dengan menggunakan sumber data primer dan juga sumber data sekunder. Peneliti mewawancarai 4 orang narasumber yaitu a. MA (45), berprofesi sebagai dosen dan ibu rumah tangga. Berdasarkan usia MA masih dalam katagori generasi y. b. SK (51), berprofesi sebagai karyawan swasta. Berdasarkan usia SK masih dalam katagori generasi X. c. TZ (19), mahasiswa, generasi milenial. D. BR (16), Pelajar SMA. Seluruh narasumber berdomisili di Jakarta. Peneliti juga melakukan observasi serta riset dokumentasi untuk memperkuat analisa penelitian ini.

\section{RESULT AND DISCUSSION}

Keempat narasumber yang peneliti wawancarai menyampaikan bahwa mereka hingga saat ini masih mendengarkan radio. Keempat narasumber yang berbeda generasi menikmati radio dengan durasi yang beragam. Durasi mendengarkan radio yang paling banyak dilakukan oleh MA dan SK yang merupakan generasi Y dan X. Namun baik MA, SK, TZ dan BR samasama senang mendengarkan radio saat dalam perjalanan. Mereka sependapat bahwa radio membuat perjalanan mereka menyenangkan karena melalui radio mereka dapat memperoleh hiburan juga berbagai informasi.

MA mengatakan bahwa durasinya mendengarkan radio justru lebih banyak dibandingkan media lainnya. MA menyatakan bahwa:

Saya tuh mendengarkan radio sambil mengerjakan pekerjaan rumah. Beberes rumah, masak sampai nyuci saya mendengarkan radio. Antar jemput anak diperjalankan mendengarkan radio.

\footnotetext{
${ }^{5}$ Lexy J Moleong, Metode Penlitian Kualitatif, (Bandung: Remaja Rosdakarya, 2003), hlm. 3
} 
BR dan TZ sebagai generasi milenial mendengarkan radio 3 Nomor 2 Tahun 2019 han hanya sekedar di perjalanan tetapi juga saat mereka sedang belajar. Sementara SK menyatakan mendengarkan radio hanya saat sedang dalam perjalanan. Pengakuan MA, SK, TZ dan BR menunjukkan bahwa keberadaan radio memberikan suasana berbeda di saat mereka dalam kondisi sibuk keseharian. Sifat radio yang auditif memudah untuk menikmati program yang disiarkan bersamaan dengan mengerjakan kegiatan lainnya. Keuntungan radio siaran bagi pendengar ialah sifatnya yang santai. Orang bisa menikmati acara siaran radio sambil makan, sambil tidur-tiduran, sambil bekerja, bahkan sambil mengemudikan mobil. ${ }^{6}$

Radio memiliki acara beragam yang disukai pendengarnya. Seluruh narasumber mengakui bahwa mereka menikmati radio sebagai media hiburan. Perjalanan yang macet bahkan membutuhkan waktu berjam-jam membuat mereka lebih merasa terhibur dnegan kehadira radio. $\mathrm{TZ}$ dan $\mathrm{BR}$ bahwa mengatakan bahwa mereka menikmati radio yang memang radionya anak muda yaitu lebih banyak menyiarkan music dibandingkan informasi. Berbeda dengan generasi di atas mereka yaitu SK dan MA yang mendengarkan radio untuk sumber informasi juga sekaligus hiburan.

Menurut MA bahwa setelah sahalat subuh ia juga mendengar ceramah agama. Sambil menyiapkan perbekalan anak sekolah ia dapat mendengarkan ceramah agama. Tentunya hal ini hanya dapat dilakukan dengan media radio.

Media radio berfungsi sebagai media penyampaian informasi yang mencakup ideology, norma, seni, ilmu pengetahuan dan agama (suemarjan 1990 : 189). Faktor usia sangatlah mempengaruhi minat dan kesenganan seseorang. Seperti hal nya dalam pemilihan program. Seperti hal nya anak muda, mereka cenderung lebih suka mendengarkan acara yang bernuansa anak muda. Seperti hal nya progam-progam hiburan ataupun program musik. Berbeda dengan mereka yang mempunyai masalah dalam kehidupannya. Terutama mereka yang sudah menginjak dewasa dan juga kehiupan berumah tangga. Mereka ingin sekali mencari solusi dari permasalahan mereka. ${ }^{7}$

Era digital membuat radio streaming dapat diakses melalui smartphone. Ke seluruh narasumber menjelaskan bahwa mereka menpergunakan smartphone untuk mendengarkan radio bilamana mereka berada di luar rumah. Namun TZ dan BR juga mengakses radio melalui laptop dan menikmati radio streaming. Sejauh ini mereka mengakui bahwa mereka menikmati radio streaming sebatas untuk hiburan belum untuk mencari informasi.

\footnotetext{
${ }^{6}$ Effendy, Uchyana, Onong. Radio Siaran Teori dan Praktek. (Bandung: Mandar Maju, 1991) hlm. 18

${ }^{7}$ Syamsul, Asep, Romli. Dasar-Dasar Siaran Radio. (Bandung: Nuansa) hlm. 21
} 

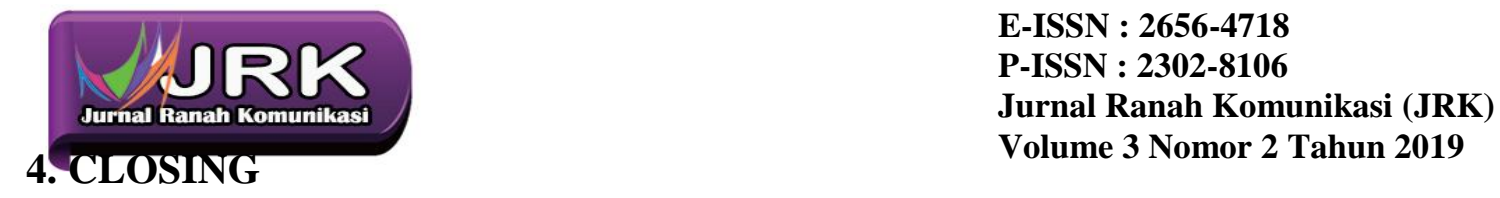

Radio masih memiliki tempat di hati pemirsanya. Sifat radio yang auditif membuat pemirsanya mampu mengerjakan kegiatan lain sekaligus. Era digital, peminat radio masih kalangan generasi $\mathrm{X}$ dan $\mathrm{Y}$. Generasi milenial yang menikmati radio sebatas untuk hiburan mendengarkan music. Mereka lebih memilih media lain untuk mengakses informasi. Radio streaming tidak selalu dinikmati oleh semua kalangan. Kalangan generasi $\mathrm{X}$ dan $\mathrm{Y}$ masih memilih radio dari smartphone mereka. Dengan saran penelitian sebaiknya pengelola radio dapat memanfaatkan perkembangan teknologi informasi dengan memanfaatkan internet serta program yang lebih inovatif. Program yang inovatif akan menambah daya tarik pemirsa menjadikan radio bukan sekedar media hiburan tetap juga media informasi.

\section{REFERENCES}

Arifin, Anwar. 1984. Strategi Komunikasi. Bandung: ARMICO

Liliweri, Alo. 1991. Komunikasi Antarpribadi. Bandung : Citra Aditya Bakti.

Effendy, Onong Uchjana. 1993. Ilmu, Teori \& Filsafat Komunikasi. Bandung : PT. Citra Aditya Bakti.

Rakhmat, Jalaluddin. 2007. Psikologi komunikasi. Bandung: PT Remaja Rosdakarya.

Syamsul, Asep dan Romli, M. 2009. Dasar-Dasar Siaran Radio, (Bandung: Nuansa, 2009)

West, Richard, Lynn H. Turner. (2008). Pengantar Teori Komunikasi: Analisis dan Aplikasi (Buku 2) (Edisi 3). Jakarta: Salemba Humanika. 